\title{
AUSGEWÄHLTE DOKTORDISSERTATIONEN
}

DER

LEIPZIGER JURISTENFAKULTÄT.

\author{
UBBER DIE \\ KOLLEKTIVPROKURA.
}

VoN

DR. JUR. FELIX BIE.

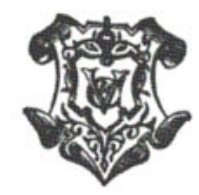

LEIPZIG, VERLAG VON VEIT \& COMP.

1894. 


\section{In halt.}

I. Einleitung:

$\$$ 1. Praktische Bedeutung

a. der Prokura im allgemeinen. . . . . . . . . . . . . . 7

b. der Kollektivprokura im besonderen . . . . . . . . . . . 8

\section{Geschichtliche Vorläufer der Kollektivprokura:}

\$ 2. Vorbemerkung. . . . . . . . . . . . . . . . . . . . 9

3. Mehrere institores und magistri navis . . . . . . . . . . . . . . . 9

\$ 4. Mehrere Bevollmächtigte nach preuß. A. L. R. und anderen bürgerlichen Gesetzbüchern

\section{Hauptteil.}

\section{Begriff und Erfordernisse der Kollektivprokura:}

§. Begriff und rechtliche Natur derselben . . . . . . . . . . . . 12

\$ 6. Kollektivprokura nicht identisch mit mehreren Einzelprokuren . . 13

$\S$ 7. Kollektivprokura nur eine subjektive Beschränkung der Prokura . 14

8. Die Vermutung gegen das Vorhandensein einer Kollektivprokura . 16

$\S 9$. Bestimmtheit ein Erfordernis der Kollektivprokura . . . . . . 17

\section{Besondere Arten der Kollektivprokura bei Handels- gesellschaften:}

§ 10. Praktischer Wert der einem Gesellschafter und einem Prokuristen gemeinschaftlich verliehenen Vertretungsbefugnis . . . . . . . 18

\$ 11. a. Der Geist des Gesetzes spricht für die Zulässigkeit solcher Verbindung . . . . . . . . . . . . . . . . . . . . . 19

b. Das Gewohnheitsrecht bestätigt dieselbe . . . . . . . . . 21

\$ 12. Ist darin eine neue Rechtsbildung oder eine Kollektivprokura zu sehen? 21

$\$ 13$. Beweis des letzteren:

a. Gleichheit der geschäftlichen Stellung keine Voraussetzung für

Kollektivprokuristen. . . . . . . . . . . . . . . . . 22

b. Bedeutungslosigkeit formeller Schwierigkeiten . . . . . . . 24

$\S$ 14. Erfordernisse derartiger Kollektivprokuren:

a. vom Standpunkte der Prokuristen . . . . . . . . . . . 25

b. vom Standpunkte der Gesellschafter. . . . . . . . . . . 26

$\$$ 15. Gesellschafter können nur Kollektiv prokuristen werden . . . . 30

§ 16. a. Beispiele aus der Praxis für Kollektivprokuren nach MaBgabe der $\$ \S 10 \mathrm{ff}$. . . . . . . . . . . . . . . . . . . . 31

b. Stellungnahme des Reichsoberhandelsgerichtes zu denselben . . 31 
Inhalt.

v. Bestellung der Kollektivprokura:

\$ 17. Arten der Bestellung . . . . . . . . . . . . . . . . . 33

$\$ 18$. Wer darf eine Kollektivprokura bestellen? . . . . . . . . . 34

\section{Umfang der Kollektivprokura :}

$\S$ 19. Der Umfang der Kollektivprokura nach Analogie der einfachen Prokura

$\$$ 20. Unmöglichkeit stillschweigender Erweiterung des Umfanges bei den in $\$ \$ 10$ ff. geschilderten Arten der Kollektivprokura. . . . . . 37

\section{Zustandekemmen rechtsverbindlicher Akte seitens der Kollektivprokuristen :}

$\$$ 21. Gemeinschaftliches Handeln eine Voraussetzung für das Zustandekommen rechtsverbindlicher Akte seitens der Kollektivprokuristen . 40

\$ 22. Unzulässigkeit der Vertretung eines Kollektivprokuristen durch einen anderen . . . . . . . . . . . . . . . . . . . . . . 42

\$ 23. Gemeinschaftlichkeit selbst bei Gefahr im Verzuge erforderlich . . 43

$\$$ 24. Ausnahmen von der Gemeinschaftlichkeit . . . . . . . . . . 46

$\$$ 25. Zeichnung der Kollektivprokuristen:

a. ordnungsmäBige . . . . . . . . . . . . . . . . . . 46

b. mangelhafte . . . . . . . . . . . . . . . . . . . 48

\$ 26. Modifikation der Zeichnung in den Fällen der $\$ \$ 10 \mathrm{ff}$. . . . . 49

\section{Eintragung der Kollektivprokura:}

§ 27. Anmeldung und Eintragung . . . . . . . . . . . . . . . 50

$\$ 28$. Wie oft müssen mehrere Kollektivprokuristen die Firma nebst ihrem Namen vor dem Handelsgerichte zeichnen? . . . . . . . . . 51

$\S 29$. Anmeldung und Eintragung von Kollektivprokuren gemäB $§ \S 10 \mathrm{ff} . \quad 53$

\section{Aufhebung der Kollektivprokura:}

§ 30. a. Anfhebungsgründe nach Analogie der einfachen Prokura . . . 54

b. Umwandlung in mehrere Einzelprokuren . . . . . . . . 55

\section{Inneres Verhältnis der Kollektivprokuristen:}

\$ 31. a. zum Prinzipal, bezw. zur Gesellschaft . . . . . . . . . . 55

b. unter einander. . . . . . . . . . . . . . . . . . 56

XI. Schlufs:

§ 32. Vorschläge de lege ferenda . . . . . . . . . . . . . . . 56 